\title{
Esposas como principais provedoras de renda familiar
}

\author{
Izabel Guimarães Marri* \\ Simone Wajnman ${ }^{\star *}$
}

\begin{abstract}
Este trabalho procura discutir um aspecto ainda pouco explorado do papel da mulher na formação dos rendimentos familiares, que é a situação na qual as esposas obtêm, no mercado de trabalho, rendimentos superiores aos de seus cônjuges. Além da descrição de características demográficas e socioocupacionais destas mulheres e de seus cônjuges, procura-se discutir as seguintes questões: como algumas das características observadas estão correlacionadas com a probabilidade de as famílias terem as esposas como principais provedoras; a não reversão dos padrões tradicionais de divisão do trabalho, já que a mulher mantém um número de horas muito maior do que seus cônjuges nas tarefas domésticas, mesmo quando é a principal provedora financeira do casal; e os diferenciais no rendimento médio de maridos e esposas provedores e a decomposição deste diferencial entre o que pode ser atribuído às características produtivas de ambos os grupos e o que é geralmente chamado de discriminação.
\end{abstract}

Palavras-chave: Esposas provedoras. Rendimento familiar. Desigualdade de rendimentos.

\section{Introdução}

A maior participação das mulheres na atividade econômica e o conseqüente crescimento da importância relativa dos rendimentos femininos têm estimulado estudos que evidenciam a posição desfavorável das mulheres no mercado de trabalho, seja pela segregação aos postos de trabalho de pior qualidade (LAVINAS, 1997; OLIVEIRA, 2003; BARROS, 2001), seja pela discriminação salarial sofrida por elas (LEME e WAJNMAN, 2000; GUIMARÃES, 2004), o que afetaria negativamente o bem-estar tanto das próprias mulheres quanto de suas famílias. Neste trabalho, procura-se discutir um aspecto ainda pouco explorado do papel da mulher na formação dos rendimentos familiares, que é a situação na qual as esposas obtêm, no mercado de trabalho, rendimentos superiores aos de seus cônjuges. Segundo os dados da PNAD de 2003, as famílias de núcleo composto (marido e esposa) perfaziam aproximadamente $66 \%$ do total das famílias brasileiras naquele ano, das quais $12 \%$ tinham a mulher como a principal provedora financeira do casal, adotando-se como conceito de principal provedor financeiro o cônjuge que obtém os rendimentos do trabalho mais elevados (WAJNMAN, 2005). Este tipo de casal, para o qual a literatura internacional tem apontado mais recentemente, vem se tornando mais freqüente

\footnotetext{
* Doutoranda do Centro de Desenvolvimento e Planejamento Regional - Cedeplar, da Universidade Federal de Minas Gerais UFMG.

** Professora do Departamento de Demografia, do Centro de Desenvolvimento e Planejamento Regional -Cedeplar, da Universidade Federal de Minas Gerais - UFMG
} 
no Brasil e suas características são ainda pouco conhecidas.

Neste trabalho, através dos dados da Pesquisa por Amostra de Domicílios PNAD, do IBGE, para 2004, identificam-se os perfis demográfico e socioocupacional dos casais cujas esposas são as principais provedoras, além de indicar como algumas características do casal estão correlacionadas com a probabilidade de que a esposa seja a provedora financeira. Discutese também a evidência de que, entre os casais nos quais a mulher é a provedora, não há de fato uma reversão dos padrões tradicionais de divisão do trabalho, já que a mulher mantém um número de horas muito maior do que seus cônjuges nas tarefas domésticas. Finalmente, estima-se o diferencial de rendimentos salariais entre esposas e maridos provedores e decompõem-se estes diferenciais entre a parcela explicada pelas diferenças nas características produtivas de homens e mulheres e a parte não explicada, a qual é chamada, usualmente, de discriminação.

Conhecer melhor o perfil destas trabaIhadoras parece importante, em primeiro lugar, porque elas subvertem o sólido estereótipo segundo o qual cabe aos homens a responsabilidade econômico-financeira das famílias, ficando para as mulheres, quando muito, o papel de "ajudá-los" nessa tarefa. Em segundo lugar, porque, enquanto um contingente nada desprezível de mulheres avança os limites da função tradicionalmente reservada a elas na divisão sexual do trabaIho, não há evidências de que seus respectivos cônjuges estejam se ajustando a essa inversão de papéis, tomando para si a responsabilidade com o trabalho doméstico. Finalmente, se estas mulheres provedoras desempenham o papel tipicamente masculino em suas famílias, mas no mercado de trabalho são discriminadas por serem do sexo feminino, suas famílias podem estar sendo duplamente penalizadas e, portanto, mereceriam especial atenção.

\section{Esposas provedoras na literatura internacional}

Enquanto no Brasil e no mundo grande atenção tem sido dada ao crescimento da participação da mulher no mercado de trabalho e à relativa redução das diferenças salariais entre os sexos, uma faceta deste contexto, conseqüência natural dessas mudanças, tem sido menos explorada: o crescente número de famílias cujas esposas são as principais provedoras do orçamento familiar.

A literatura existente sobre o tema indica que o padrão "tradicional" dos casais, segundo o qual os homens têm a função de principal provedor da renda familiar, tem dado espaço a um novo padrão em que as mulheres não só contribuem com parte significativa do orçamento familiar, como também, em muitos casos, são seus principais provedores (CROMPTOM; GERAN, 1995; WINKLER; MCBRIDE; ANDREWS, 2005; WINKLER, 1998; MOORE, 1990).

A mudança do status da esposa na composição da renda familiar traz consigo alterações nos papéis desempenhados por estas no mercado de trabalho, nos casamentos e nas famílias. $O$ aumento na renda de um dos parceiros, digamos da mulher, relativamente aos rendimentos do marido, eleva, teoricamente, seu poder de barganha. Esposas que recebem mais do que seus maridos têm maior poder de decisão, reduzem o tempo alocado em trabalhos domésticos e suas carreiras são tratadas como as mais importantes (IZRAELI, 1994; JOHN; SHELTON, 1997; KAMO, 1988; STEIL apud DEUTSCH; ROKSA; MEESKE, 2003). No entanto, apesar de a influência das ren-das absoluta e relativa dos cônjuges ser essencial para definir a divisão do poder na família, esse pode ser diminuído na presença de ideologias referentes a gênero (BLUMBERG; COLEMAN apud DEUTSCH; ROKSA; MEESKE, 2003).

Deutsch, Roksa e Meeske (2003), em uma ampla revisão bibliográfica sobre o tema, colocam que a questão do gênero nas relações entre os cônjuges é produzida e reproduzida dentro das famílias, à medida que os papéis e normas tradicionalmente definidos são reforçados pelos cônjuges. Os homens tendem a aceitar a participação de suas esposas no mercado de trabalho, mas preferem ganhar mais do que elas, ou, pelo menos, não depender de suas rendas (ZUO apud DEUTSCH; ROKSA; MEESKE, 2003). 
Além disso, receber mais do que os maridos não necessariamente reduz as horas dedicadas às atividades domésticas. Ainda que trabalhando o mesmo número de horas por dia, as mulheres despendem muito mais tempo nos afazeres domésticos do que seus maridos (BIANCHI; ROBINSON; SAYER apud BITTMAN; ENGLAND; FOLBRE; SAYER; MATHESON, 2003). Com o crescimento da participação dos rendimentos femininos na renda do casal, as mulheres diminuem o tempo gasto nos trabalhos domésticos, com conseqüente aumento do tempo despendido pelo marido, até o ponto em que dividem o orçamento familiar. A partir daí, em muitos casos, as mulheres absorvem uma parcela ainda maior de trabalhos domésticos para compensar o maior rendimento e o desvio de uma situação padrão da divisão das tarefas familiares (este é o caso, por exemplo, de $86 \%$ das famílias em que as mulheres ganham mais do que seus maridos na Austrália) (ATKINSON; BOLES apud BITTMAN; ENGLAND; FOLBRE; SAYER; MATHESON, 2003).

Nos Estados Unidos, a contribuição média do rendimento das esposas na renda familiar passou de $26,6 \%$, em 1970 , para $35,2 \%$, em 2003. Considerando as famílias com duplo rendimento (da esposa e do marido), a participação das mulheres norteamericanas que ganham mais do que seus cônjuges aumentou de $17,8 \%$, em 1987 , para 25,2\%, em 2003 (US BUREAU OF STATISTICS, 2005) e, para as canadenses, cresceu de $11 \%$ para $25 \%$, entre 1967 e 1993 (CROMPTOM; GERAM, 1995).

O aumento no número de esposas que ganham mais do que seus maridos está relacionado, no Canadá, com o movimento de longo prazo das mulheres para ocupações de maior rendimento, com a experiência acumulada por elas no mercado de trabalho e com a recessão que afetou sobremaneira os empregos ocupados, em sua maioria, por homens, contribuindo para colocar as mulheres na situação de primeiras provedoras do lar (CROMPTON; GERAN, 1995).

Nos EUA as principais características dos casais com sobre-rendimento das esposas, que persistem nesta situação, são o maior nível educacional das mulheres, em relação a seus maridos, o menor número de crianças com menos de cinco anos na família e o maior percentual de maridos com algum tipo de doença em relação às famílias em que o marido é o principal provedor (WINKLER; MCBRIDE; ANDREWS, 2005). ${ }^{1}$ Estas famílias também concentram-se nos quintis mais baixos da renda familiar (WRINKLER, 1998).

Enfim, já que grande parte dos rendimentos familiares é proveniente do trabalho, a sub-remuneração das esposas provedoras afeta o bem-estar financeiro de suas famílias e o reduz comparativamente ao daquelas cujo provedor principal é o marido. Descrever quem seriam, no Brasil, as esposas que são as principais provedoras de suas famílias, o diferencial entre os rendimentos dessas mulheres e os dos maridos provedores e algumas características relacionadas à família que aumentam a probabilidade de as esposas serem as principais provedoras financeiras do casal, são questões investigadas, que serão apresentadas nas próximas seções.

\section{Metodologia e base de dados}

Os dados analisados neste trabalho foram obtidos da Pesquisa Nacional por Amostra de Domicílios - PNAD, de 2004, para a região urbana do Brasil. ${ }^{2}$ As análises foram feitas com base em três medidas de renda: o rendimento de todos os trabalhos, o rendimento do trabalho principal e o salário-hora de cada um dos cônjuges.

Além de apresentar uma ampla análise descritiva dos dados, é decomposta a diferença entre o rendimento do trabalho

\footnotetext{
'Estes autores também verificam que coortes mais novas não possuem maior tendência de serem "não tradicionais", em relação às coortes mais velhas.

${ }^{2} \mathrm{~A}$ análise limita-se às famílias urbanas, uma vez que a dinâmica de participação na atividade econômica, tanto quanto de composição familiar da renda, é inteiramente distinta nos contextos urbanos e rurais.
} 
principal de esposas e maridos provedores, buscando identificar a parcela do diferencial explicada por diferenças nas suas características produtivas entre os dois grupos e a diferença não explicada, comumente atribuída à discriminação. $O$ modelo de regressão de mínimos quadrados para a equação de salário foi utilizado na decomposição dos diferenciais de rendimentos de maridos e esposas provedores, utilizando-se como variável resposta o logaritmo do rendimento mensal do trabalho principal de cada um. $O$ método de decomposição corresponde ao método de Oaxaca, largamente usado nos estudos que procuram medir a discriminação no mercado de trabalho (LEME; WAJNMAN, 2001). Através do modelo Logit, procurou-se analisar as características das famílias que aumentam a probabilidade de a esposa ser a principal provedora financeira do casal. As variáveis de análise e/ou de controle nos modelos estatísticos foram selecionadas com base na literatura existente sobre os determinantes dos diferencias de rendimentos entre homens e muIheres, no Brasil e no mundo.

\section{A composição das famílias}

Em 2004, as famílias de núcleo composto (chefe e cônjuge), da região urbana, perfaziam $63,6 \%$ do total de famílias. Os demais arranjos familiares $(36,4 \%)$ eram constituídos pelas situações em que há a presença do responsável (ou chefe) da família, sem haver presença de cônjuge (Tabela 1). Entre as famílias de núcleo composto, $44 \%$, ou $27,5 \%$ do total de famílias, possuíam duplo rendimento do trabalho, ou seja, ambos os cônjuges eram ativos e tinham rendimento do trabalho, na semana de referência da pesquisa. ${ }^{3}$ Considerando a totalidade destas famílias, as esposas eram responsáveis por $33 \%$ da renda total, os maridos por $61 \%$ e os filhos por $6 \%$.

Adotando-se o conceito de principal provedor como o cônjuge com rendimentos do trabalho superiores a $50 \%$ dos rendimentos do trabalho do casal, verifica-se que, do conjunto de famílias com duplo rendimento do trabalho, em $17 \%$ as esposas eram suas principais provedoras, perfazendo um total de 2.189.457 famílias.

TABELA 1

Distribuição das famílias, segundo composição do núcleo Brasil (1) -2004

\begin{tabular}{|c|c|c|c|}
\hline Composição do núcleo & № de famílias & $\begin{array}{l}\text { \% em relação ao } \\
\text { total de famílias }\end{array}$ & $\begin{array}{c}\text { \% em relação às } \\
\text { famílias com duplo } \\
\text { rendimento do } \\
\text { trabalho }\end{array}$ \\
\hline Total de famílias & 46.731 .207 & 100,0 & (2) \\
\hline Famílias só com chefes & 17.011 .555 & 36,4 & (2) \\
\hline Chefes homens & 3.985 .940 & 23,0 & (2) \\
\hline Chefes mulheres & 13.025 .615 & 77,0 & (2) \\
\hline Famílias com chefe e conjuge (casais) & 29.719.652 & 63,6 & (2) \\
\hline Chefes homens & 27.859 .318 & 94,0 & (2) \\
\hline Chefes mulheres & 1.860 .334 & 6,0 & (2) \\
\hline Casais com duplo rendimento do trabalho & 12.843.968 & 27,5 & 100,0 \\
\hline Chefes homens & 11.932 .046 & 93,0 & 93,0 \\
\hline Chefes mulheres & 911.922 & 7,0 & 7,0 \\
\hline Casais cujas esposas são as principais provedoras & 2.189 .457 & 4,7 & 17,0 \\
\hline Chefes homens & 1.911 .752 & 87,0 & 15,0 \\
\hline Chefes mulheres & 277.705 & 13,0 & 2,0 \\
\hline
\end{tabular}

Fonte: IBGE. Pesquisa Nacional por Amostra de Domicílios - PNAD 2004.

(1) Corresponde somente à área urbana.

(2) Percentual calculado apenas para casais com duplo rendimento do trabalho.

${ }^{3}$ Para fins de comparação entre os rendimentos dos cônjuges, excluíram-se os casais com rendimento total do trabalho (do chefe e do cônjuge) igual a zero. 
É interessante notar que, embora cresça a importância relativa das mulheres como principais provedoras financeiras das famílias, as pesquisas domiciliares continuam apontando, na maioria esmagadora dos casos, os homens como os chefes ou responsáveis pelas famílias constituídas por casais com ou sem filhos (Tabela 1). A posição de chefe (ou de pessoa de referência, como passa a se chamar essa posição a partir da PNAD de 1992) é definida pelos próprios entrevistados com base em sua percepção e não necessariamente por um critério econômico-financeiro. Com base nessa percepção, na PNAD 2004, 93\% das famílias com casais declaravam seu responsável como sendo um indivíduo de sexo masculino. Mesmo entre os 2.189 mil casais nos quais os rendimentos femininos eram superiores aos masculinos, em apenas 13\% deles a responsabilidade foi atribuída à mulher. Considerando-se que a noção de responsabilidade dificilmente está associada aos encargos do trabalho doméstico, porque se assim fosse as mulheres não estariam tão sub-representadas nessa categoria, e que, pelo menos neste caso, a responsabilidade tampouco é financeira, resta apenas a justificativa cultural que relega à mulher o papel secundário na hierarquia familiar, mesmo quando a ela cabem os cuidados não só com os familiares e a estrutura física da residência, mas também com a provisão financeira da família.

Para situar as famílias por grupos de renda, calculou-se a renda familiar per capita, líquida da renda das esposas, ou seja, foram consideradas a renda total dos maridos e dos filhos de todas as famílias com núcleo composto (Gráfico 1) e a daquelas com núcleo composto e duplo rendimento do trabalho (Gráfico 2), dividindo cada um dos dois grupos em 10 decis. A partir desta distribuição por decil de renda, observou-se a participação do rendimento das esposas na renda total do trabalho do casal. Como era de se esperar, os dados do Gráfico 1 mostram que uma grande parcela das esposas não participava no orçamento familiar com rendimentos do

\section{GRÁFICO 1}

Participação do rendimento das esposas no rendimento total do casal, segundo decis de renda familiar per capita, líquida da renda das esposas, para casais com núcleo composto Brasil (1) - 2004

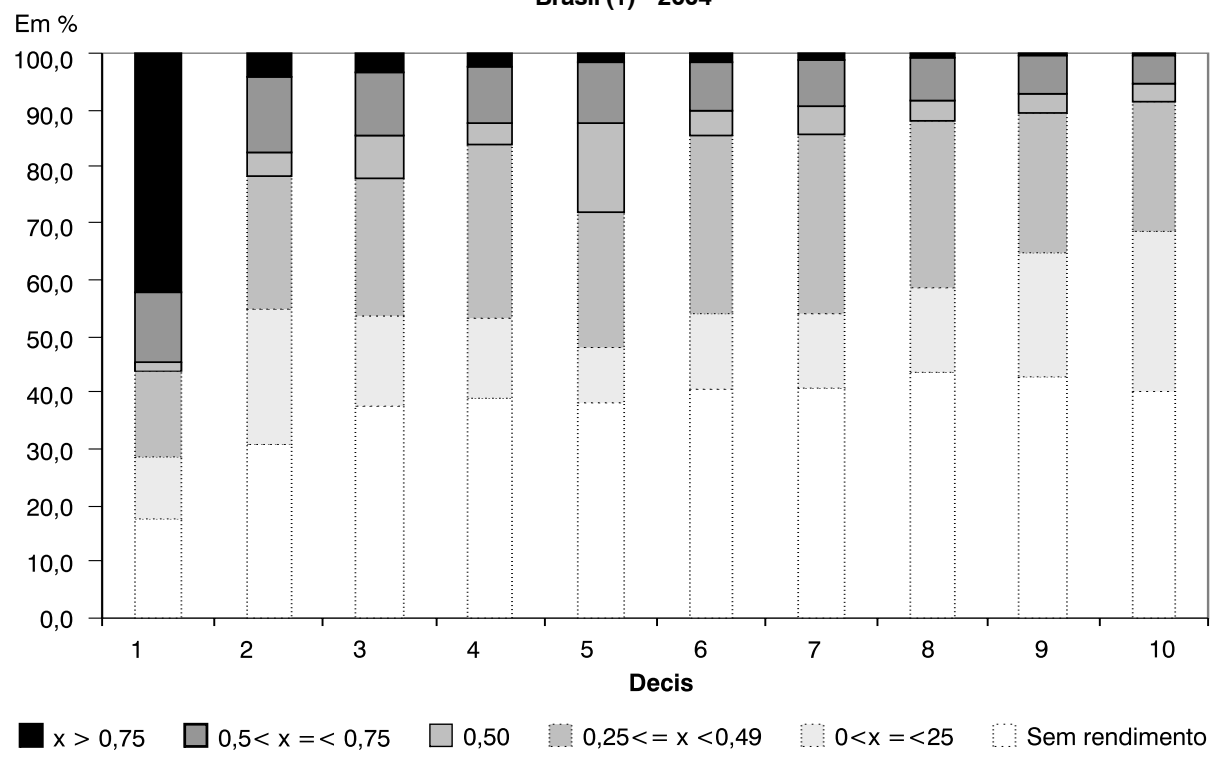

Fonte: IBGE. Pesquisa Nacional por Amostra de Domicílios - PNAD 2004.

(1) Corresponde somente à área urbana. 
GRÁFICO 2

Participação do rendimento das esposas no rendimento do trabalho do casal, segundo decis de renda familiar per capita, líquida da renda das esposas, para casais com duplo rendimento do trabalho Brasil (1) - 2004

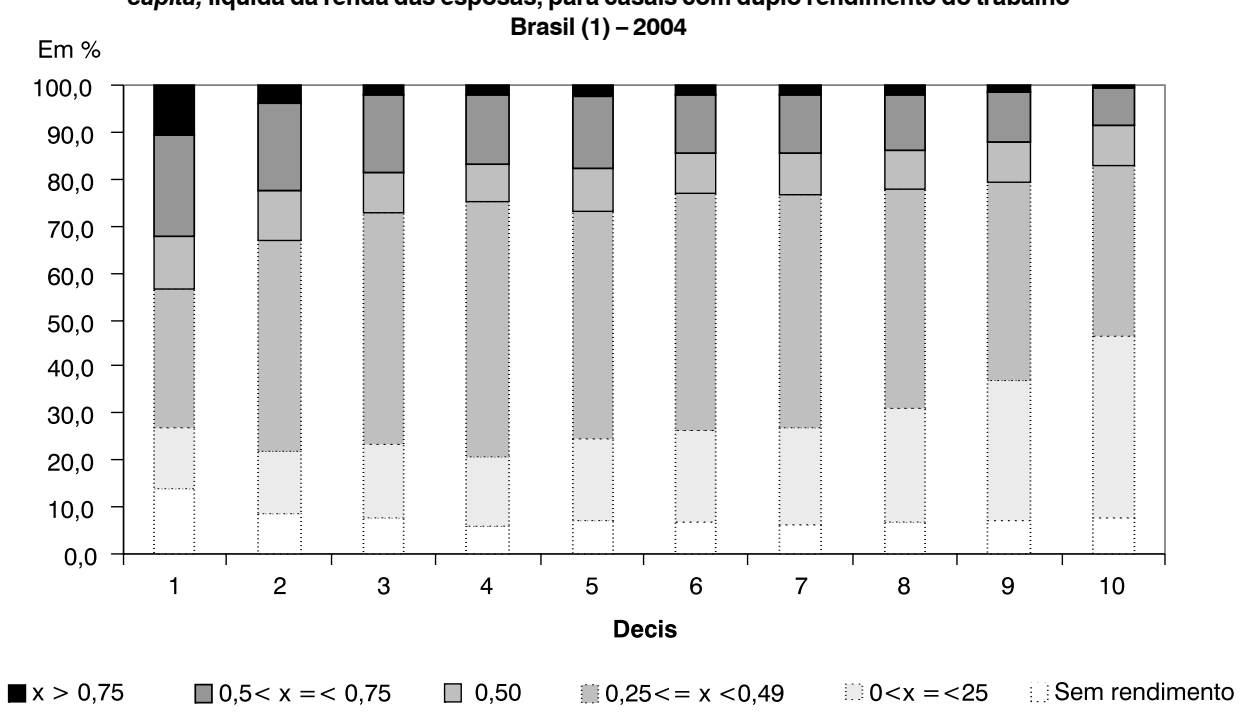

Fonte: IBGE. Pesquisa Nacional por Amostra de Domicílios - PNAD 2004.

(1) Corresponde somente à área urbana.

trabalho (em aproximadamente $37 \%$ do total das famílias), dada a ainda grande inatividade feminina no mercado de trabalho. É interessante notar, no entanto, que este percentual é bem menor no primeiro decil da renda, no qual também é possível verificar a maior participação do rendimento das esposas, notadamente com mais de $75 \%$ da renda do casal. À medida que se avança nos decis de renda, a participação das esposas na renda do trabalho do casal diminui.

Ao se reduzir a amostra e considerar somente as famílias com casais com duplo rendimento do trabalho (em que ambos são ativos, mas um dos cônjuges pode ter rendimento zero), o percentual de esposas que não participam da renda do casal diminui bastante (Gráfico 2). Destas famílias, 17\% tinham a esposa como principal provedora, ganhando mais de $50 \%$ da renda do casal. Aproximadamente um quinto destas famílias estava situado no primeiro decil, valor que tende a diminuir à medida que se avança nos decis de renda. O primeiro decil ainda é o grupo em que as esposas têm maior participação no orçamento do casal, com mais de $50 \%$ ou $75 \%$ deste. No entanto, observa-se que a existência de famílias com esposas provedoras não se limita aos estratos socioeconômicos mais pobres, estando representadas em toda a distribuição. A concentração quase exclusiva delas nos grupos menos favorecidos encontra-se nos casos em que as mulheres são praticamente as únicas provedoras.

\section{Esposas provedoras no Brasil}

De acordo com os dados analisados, as esposas provedoras eram, em média, dois anos mais velhas (possuíam 39 anos de idade) do que as co-provedoras, ${ }^{4} 56 \%$ declararam-se como da cor branca ${ }^{5}$ e tinham, aproximadamente, 9,5 anos de estudo. A maior parte das co-provedoras também se declarou como branca (60\%) e com uma média de 8,2 anos de estudo. Os maridos, por sua vez, para ambos os gru-

${ }^{4}$ Entende-se como co-provedor o cônjuge que aporta com menos de $50 \%$ da renda do casal.

${ }^{5}$ Utilizou-se a variável dummy de cor como branca e não branca, agrupando os pretos, amarelos, pardos e indígenas. 
pos, possuíam entre 7 e 8 anos de estudos, ou seja, mesmo os maridos provedores principais da renda dos casais tinham menor escolaridade do que as mulheres provedoras. Esta informação será especialmente importante para analisar os diferenciais de rendimento entre esposa e marido provedores.

Quando questionadas se despendiam algum tempo nos afazeres domésticos, 95\% das esposas provedoras responderam gastar, em média, 21 horas semanais nas tarefas da casa, enquanto $97 \%$ das co-provedoras o faziam, em média, por 25 horas semanais (Tabela 2). Entre os maridos das primeiras, $64 \%$ declararam se dedicar, aproximadamente, 11 horas semanais nas atividades domésticas, enquanto $52 \%$ dos maridos das segundas (os provedores) gastavam menos de dez horas semanais. Os resultados mostram que, apesar de aumentar o percentual de maridos que se dedicavam ao trabalho doméstico quando as esposas eram a principal provedora financeira, o tempo despendido por elas continua muito maior do que o deles e não se reduziu significativamente em relação às co-provedoras. Estes dados corroboram os resultados das pesquisas internacionais, até o ponto em que mostram que as esposas, de um modo geral, fazem a maior parte do trabalho doméstico (ver, por exemplo, BITTMAN; ENGLAND; FOLBRE; SAYER; MATHESON, 2003), no entanto, não sugerem um aumento na participação dos maridos, ou uma divisão mais igualitária dos afazeres domésticos, quando estes contribuem menos com o orçamento familiar.
Os números médios de filhos e de filhos com menos de sete anos de idade nas famílias também foram analisados e não apresentaram grandes diferenças entre as famílias providas pelas esposas e aquelas providas pelos maridos.

Uma característica das famílias providas pelas esposas era a existência de um percentual um pouco maior de maridos aposentados pelo Instituto de Previdência Privada (8\%), em relação às demais famílias (4\%). Como a renda da aposentadoria é um incentivo para a desocupação, nestes casos há maior probabilidade de o marido ser desocupado, o que, em parte, explicaria a sobre-renda feminina.

Em relação à ocupação das esposas provedoras, apesar de estarem concentradas no grupo trabalhadores dos serviços (29\%), que engloba um grande contingente de trabalhadoras dos serviços domésticos, elas estavam sub-representadas nesta categoria quando comparadas ao total de esposas das famílias com duplo rendimento do trabalho. Por outro lado, estavam superrepresentadas nos grupos dirigentes em geral, professores das ciências e das artes e técnicos do nível médio e, em muito maior medida, no grupo membros das Forças Armadas e auxiliares (Gráfico 3).

Considerando-se apenas as mulheres que ganhavam mais de $75 \%$ da renda do casal, verificou-se sua concentração no grupo referente aos trabalhadores dos serviços $(30 \%)$, apesar de ainda estarem sub-representadas em relação ao total das famílias analisadas, e os mesmos grupos

TABELA 2

Dedicação ao trabalho doméstico e horas despendidas nessa atividade, por sexo do provedor principal do casal Brasil (1) - 2004

\begin{tabular}{lccc}
\hline Dedicação ao trabalho doméstico e horas despendidas & $\begin{array}{c}\text { Casais com } \\
\text { esposas } \\
\text { provedoras }\end{array}$ & $\begin{array}{c}\text { Casais com } \\
\text { maridos } \\
\text { provedores }\end{array}$ & Total das famílias \\
\hline $\begin{array}{l}\text { \% dos que se dedicavam } \\
\text { Esposas }\end{array}$ & 95,0 & 97,0 & 96,0 \\
Maridos & 64,0 & 52,0 & 55,0 \\
Horas dedicadas & & & 25,01 \\
Esposa & 20,98 & 25,01 & 9,59 \\
Maridos & 11,40 & 9,59 & \\
\hline
\end{tabular}

Fonte: IBGE. Pesquisa Nacional por Amostra de Domicílios - PNAD 2004.

(1) Corresponde somente à área urbana. 


\section{GRÁFICO 3}

Relação entre o número de esposas provedoras e o número total de esposas, em casais com duplo rendimento do trabalho, por grupos de atividade Brasil (1) - 2004

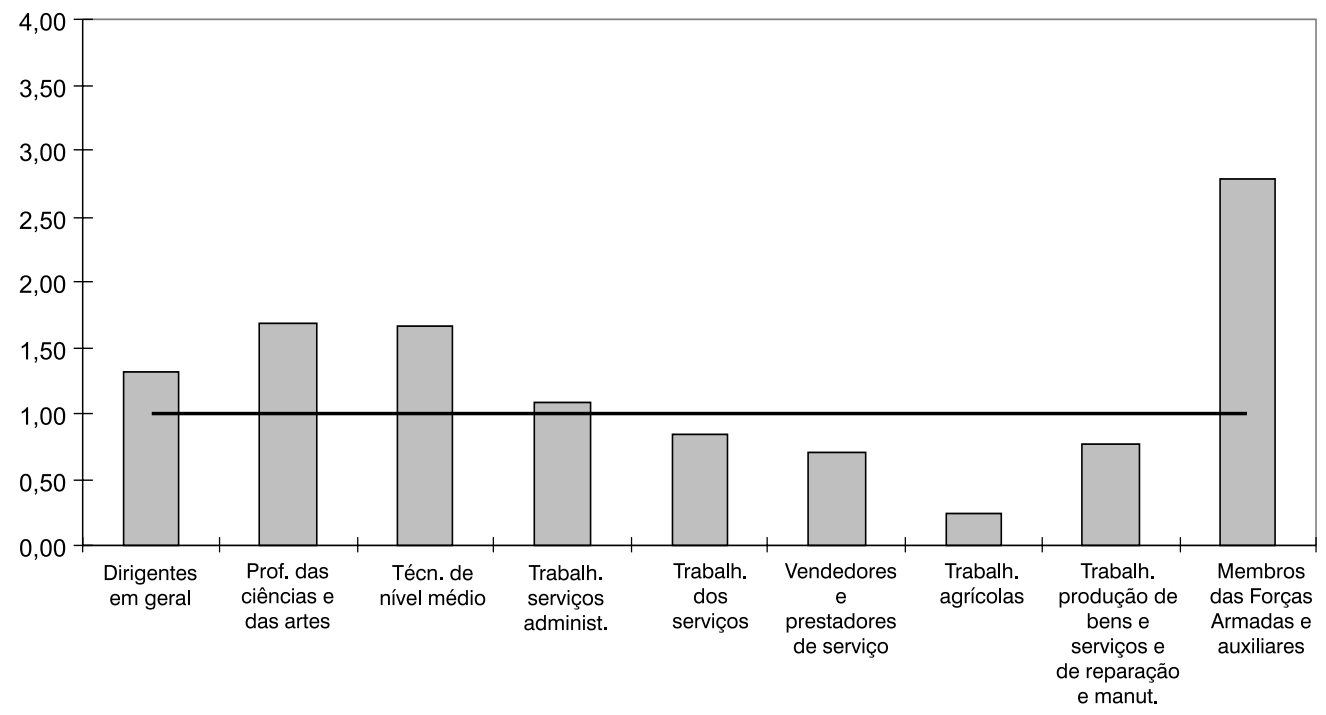

Fonte: IBGE. Pesquisa Nacional por Amostra de Domicílios - PNAD 2004.

(1) Corresponde somente à área urbana.

\section{GRÁFICO 4}

Relação entre o número de esposas que ganham mais de $75 \%$ da renda do casal e o número total de esposas, em casais com duplo rendimento do trabalho, por grupos de atividade

\section{Brasil (1) -2004}

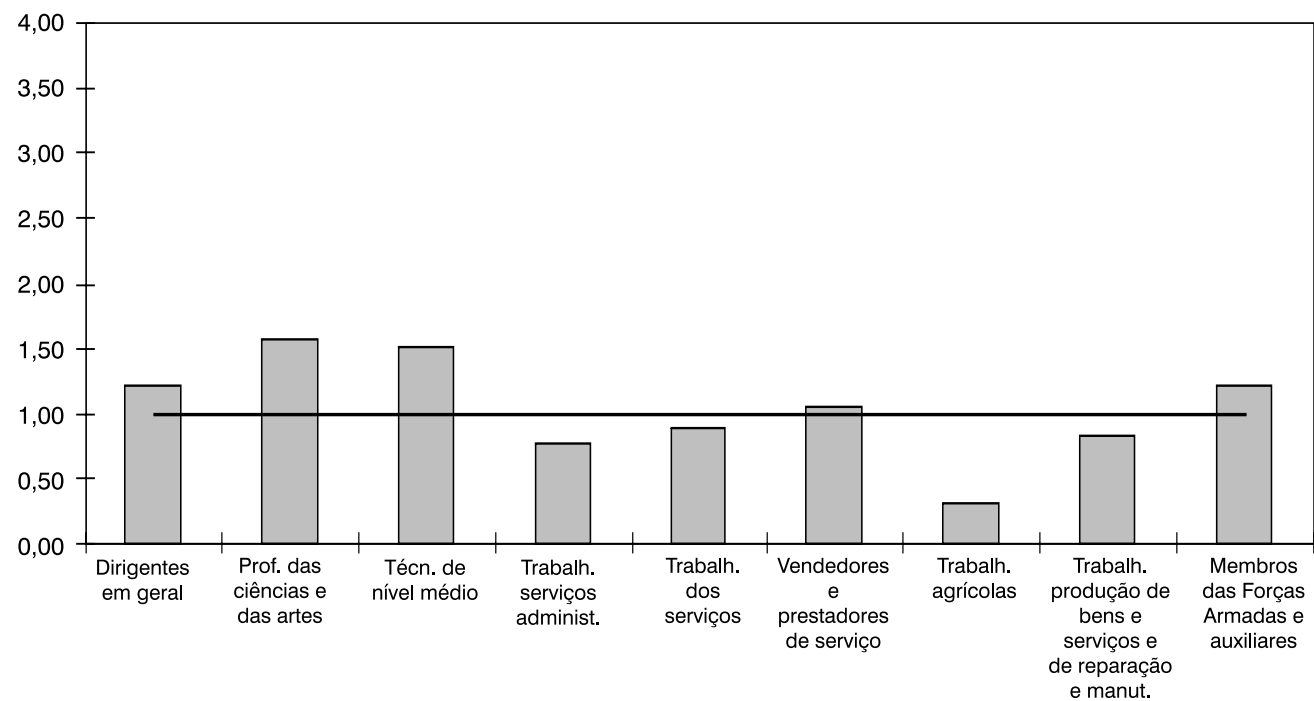

Fonte: IBGE. Pesquisa Nacional por Amostra de Domicílios - PNAD 2004.

(1) Corresponde somente à área urbana. 


\section{GRÁFICO 5}

Relação entre o número de maridos co-provedores e o número total de maridos, em casais com duplo rendimento do trabalho, por grupos de atividade Brasil (1) - 2004

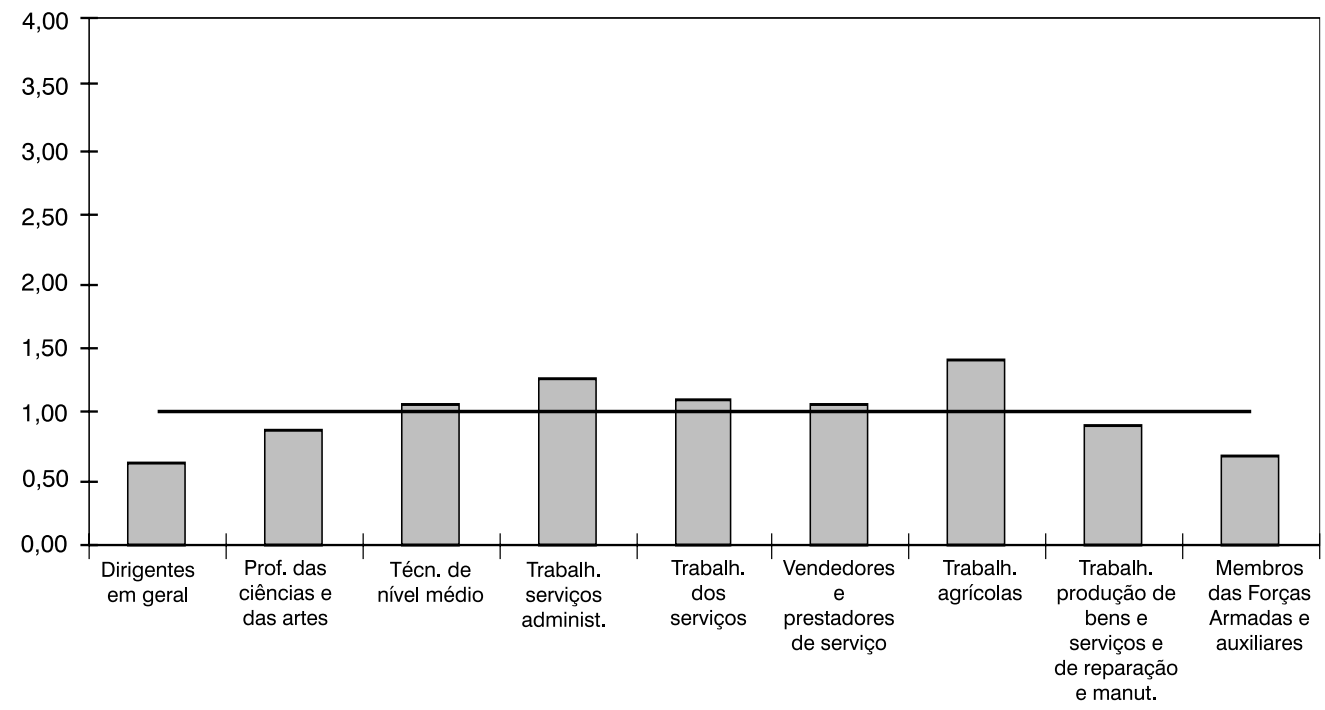

Fonte: IBGE. Pesquisa Nacional por Amostra de Domicílios - PNAD 2004.

(1) Corresponde somente à área urbana.

GRÁFICO 6

Relação entre o número de maridos que ganham até $25 \%$ da renda do casal e o total de maridos, em casais com duplo rendimento do trabalho, por grupos de atividade

\section{Brasil (1) - 2004}

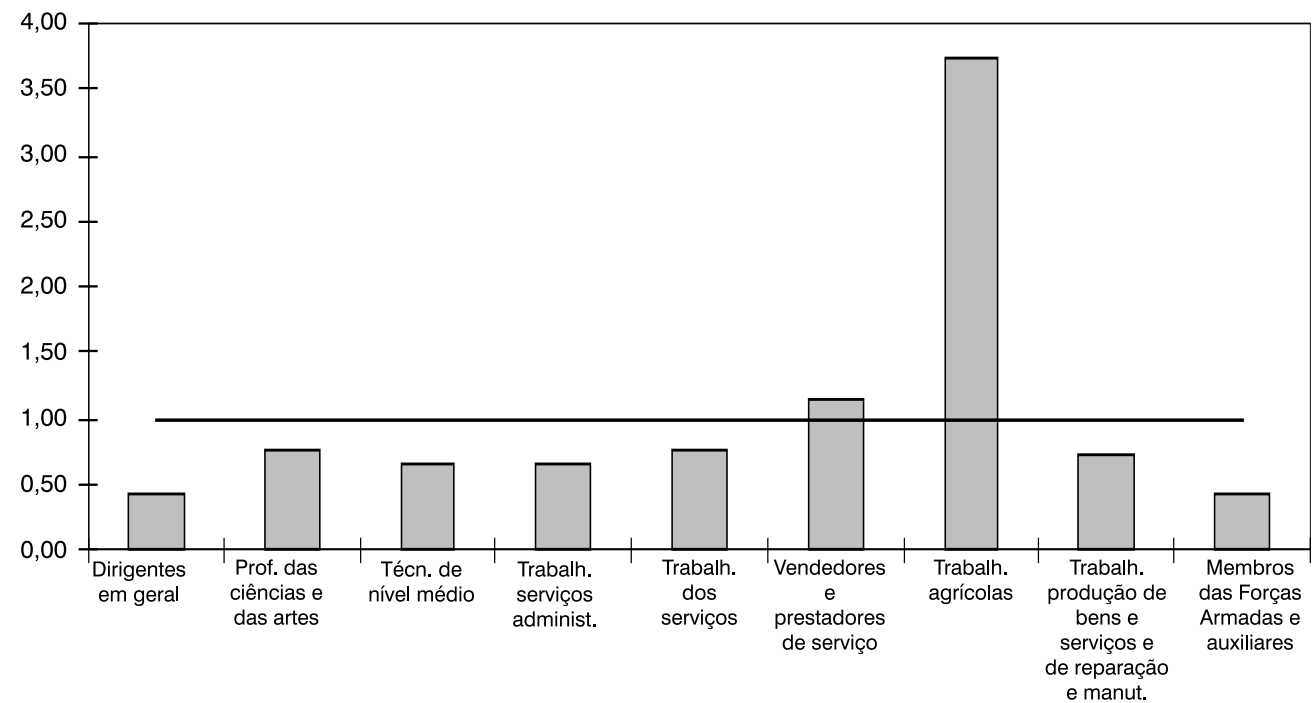

Fonte: IBGE. Pesquisa Nacional por Amostra de Domicílios - PNAD 2004.

(1) Corresponde somente à área urbana. 
de ocupações se destacaram em relação às esposas de todas as famílias, com exceção do grupo dos membros das Forças Armadas, que perdeu um pouco sua representatividade, e do grupo das vendedoras e prestadoras de serviços, que ganhou maior importância (Gráfico 4).

Os maridos das esposas provedoras, por sua vez, concentravam-se no grupo de trabalhadores da produção de bens e serviços e de reparação e manutenção (30\%). Em relação ao total de maridos das famílias em análise, eles estavam muito menos representados nos grupos de dirigentes em geral e membros das Forças Armadas e especialmente sobre-representados nos grupos de trabalhadores dos serviços administrativos e trabalhadores agrícolas (Gráfico 5).

Os maridos que ganhavam até $25 \%$ da renda do casal concentravam-se nos trabalhos agrícolas (33\%), estando, sem dúvida, super-representados em relação ao total dos maridos (Gráfico 6). ${ }^{6}$

Com o intuito de captar as características das famílias que aumentavam a probabilidade de as esposas serem as principais provedoras financeiras, utilizou-se o modelo Logit, em que a variável resposta do modelo indica se a esposa é ou não a provedora do casal, mantendo o critério de que provedor é o cônjuge com maior rendimento total dos trabalhos. A medida proveniente da renda de todos os trabalhos, ao contrário da renda do trabalho principal, ou do salário-hora, indica a contribuição de cada um dos cônjuges no orçamento familiar e, por isso, parece ser uma medida adequada para esta análise, a partir da qual se quer definir quais as características que fazem as famílias possuírem as esposas como as principais provedoras financeiras.

Neste modelo interessaram não somente as características de cada um dos cônjuges, mas também a relação entre elas. Desta forma, as variáveis de controle do modelo incluíram: idade contínua da esposa e diferença de idade entre os cônjuges; ${ }^{7}$ diferença em anos de estudo entre os cônjuges e dummies para grupos de anos de estudo das esposas (categoria de referência: 0-3 anos de estudo); $;$ quatro dummies para a combinação de cor/raça do casal (categoria de referência: casal branco); ${ }^{9}$ dummies para as regiões do país (categoria de referência: Sudeste); dummies para grupos ocupacionais da esposa e do marido (categoria de referência: trabalhadores dos serviços) $;{ }^{10}$ variável dummy do marido ser aposentado e/ou pensionista pelo Instituto de Previdência Privada; e dummies para os quartis da renda familiar per capita em que se encontra a família.

Os resultados da regressão, demonstrados no Quadro 1, permitem inferir que, segundo o coeficiente obtido pela variável contínua da diferença de escolaridade entre os cônjuges, estatisticamente significativa a $5 \%$ de significância, quanto mais escolarizada a esposa em relação a seu marido, controlando pelas demais covariáveis, maior era a probabilidade dela ser a principal provedora do casal. As variáveis dummy para os grupos de 12 a 15 e mais anos de estudo indicam que, controlando pelas demais variáveis do modelo, famílias em que as mulheres apresentavam escolaridade igual ou superior a 12 anos de estudo possuíam probabilidade crescente e maior de a esposa ser a prin-

\footnotetext{
${ }^{6}$ Note-se que, apesar de limitar a amostra aos residentes do setor urbano, os postos de trabalho para ocupações agrícolas são parte expressiva do emprego de mais baixa remuneração.

${ }^{7}$ A idade é considerada, de acordo com a teoria do Capital Humano, uma proxy da experiência adquirida no mercado de trabalho. O perfil dos rendimentos tende a variar no ciclo de vida das pessoas, sendo necessária a inclusão desta variável no modelo.

${ }^{8}$ Os grupos de anos de estudo foram definidos como : 0 a 3 anos; 4 a 7 anos; 8 a 11 anos; 12 a 14 anos e 15 e mais anos de estudo.

${ }^{9}$ As dummies criadas foram: casal branco; esposa branca e marido não branco; esposa não branca e marido branco; casal não branco.

${ }^{10}$ Os grupos ocupacionais incluíram: Dirigentes em Geral; Professores das Ciências e das Artes; Técnicos de Nível Médio; Trabalhadores dos Serviços Administrativos; Trabalhadores dos Serviços; Vendedores e Prestadores de Serviço; Trabalhadores Agrícolas; Trabalhadores da Produção de Bens e Serviços e de Reparação e Manutenção; e Membros das Forças Armadas e Auxiliares.
} 


\begin{tabular}{|c|c|c|c|c|c|}
\hline \multicolumn{6}{|c|}{$\begin{array}{c}\text { QUADRO 1 } \\
\text { Resultado do modelo Logit } \\
\text { Brasil (1) - 2004 }\end{array}$} \\
\hline \multicolumn{2}{|c|}{$\begin{array}{l}\text { Logistic regression } \\
\text { (sum of wgt is } 1.2844 \mathrm{e}+07 \text { ) } \\
\text { Iteration 5: log pseudolikelihood }=-11599.907 \\
\text { Log pseudolikelihood }=-11599.907\end{array}$} & \multirow{2}{*}{\multicolumn{2}{|c|}{$\begin{array}{c}\text { Number of obs } \\
\text { Wald chi2(34) } \\
\text { Prob > chi2 } \\
\text { Pseudo R2 } \\
\text { Desv. Pad. }\end{array}$}} & \multicolumn{2}{|c|}{$\begin{array}{lr}= & 28114 \\
= & 1645.61 \\
= & 0.0000 \\
= & 0.0964\end{array}$} \\
\hline Descrição & Covariáveis & & & $z$ & $\mathrm{P}>\mathrm{Z}$ \\
\hline Idade & $\begin{array}{l}\text { Idade esposas } \\
\text { Dif. Idade (esposa-marido) }\end{array}$ & $\begin{array}{l}0,01 \\
0,02\end{array}$ & $\begin{array}{l}0,00 \\
0,00\end{array}$ & $\begin{array}{l}5,75 \\
7,17\end{array}$ & $\begin{array}{l}0,00 \\
0,00\end{array}$ \\
\hline Cor & $\begin{array}{l}\text { Ela branca/ele não branco } \\
\text { Ambos não brancos } \\
\text { Ela não branca/ele branco }\end{array}$ & $\begin{array}{l}0,21 \\
0,25 \\
0,19\end{array}$ & $\begin{array}{l}0,06 \\
0,05 \\
0,07\end{array}$ & $\begin{array}{l}3,50 \\
4,99 \\
2,92\end{array}$ & $\begin{array}{l}0,00 \\
0,00 \\
0,00\end{array}$ \\
\hline Educação & $\begin{array}{l}\text { Dif. Educ. (esposa - marido) } \\
\text { educ47 esposa } \\
\text { educ811 esposa } \\
\text { educ1214 esposa } \\
\text { educ15 esposa }\end{array}$ & $\begin{array}{r}0,08 \\
(0,08) \\
(0,10) \\
0,21 \\
0,50\end{array}$ & $\begin{array}{l}0,01 \\
0,07 \\
0,08 \\
0,11 \\
0,11\end{array}$ & $\begin{array}{r}11,76 \\
(1,11) \\
(1,28) \\
1,90 \\
4,67\end{array}$ & $\begin{array}{l}0,00 \\
0,27 \\
0,20 \\
0,06 \\
0,00\end{array}$ \\
\hline $\begin{array}{l}\text { Ocupações } \\
\text { Marido }\end{array}$ & $\begin{array}{l}\text { Dirigentes em geral } \\
\text { Prof. das ciências e das artes } \\
\text { Técn. de nível médio } \\
\text { Trabalh. dos serviços administ. } \\
\text { Vendedores e prestadores de serviço } \\
\text { Trabalh. agrícolas } \\
\text { Trabalh. produção de bens e serviços e de manut. } \\
\text { Membros das Forças Armadas e auxiliares }\end{array}$ & $\begin{array}{r}(1,27) \\
(0,98) \\
(0,44) \\
(0,04) \\
(0,14) \\
0,50 \\
(0,29) \\
(1,01)\end{array}$ & $\begin{array}{l}0,10 \\
0,11 \\
0,08 \\
0,09 \\
0,08 \\
0,08 \\
0,06 \\
0,18\end{array}$ & $\begin{array}{r}(13,03) \\
(8,79) \\
(5,18) \\
(0,41) \\
(1,87) \\
6,37 \\
(5,07) \\
(5,61)\end{array}$ & $\begin{array}{l}0,00 \\
0,00 \\
0,00 \\
0,68 \\
0,06 \\
0,00 \\
0,00 \\
0,00\end{array}$ \\
\hline $\begin{array}{l}\text { Ocupações } \\
\text { Esposa }\end{array}$ & $\begin{array}{l}\text { Dirigentes em geral } \\
\text { Prof. das ciências e das artes } \\
\text { Técn. de nível médio } \\
\text { Trabalh. dos serviços administ. } \\
\text { Vendedores e prestadores de serviço } \\
\text { Trabalh. agrícolas } \\
\text { Trabalh. produção de bens e serviços e de manut. } \\
\text { Membros das Forças Armadas e auxiliares }\end{array}$ & $\begin{array}{r}1,05 \\
0,95 \\
0,95 \\
0,56 \\
(0,14) \\
(2,09) \\
(0,06) \\
2,21\end{array}$ & $\begin{array}{l}0,09 \\
0,08 \\
0,07 \\
0,07 \\
0,07 \\
0,17 \\
0,07 \\
0,35\end{array}$ & $\begin{array}{r}11,11 \\
11,89 \\
13,54 \\
7,78 \\
(1,96) \\
(12,16) \\
(0,86) \\
6,29\end{array}$ & $\begin{array}{l}0,00 \\
0,00 \\
0,00 \\
0,00 \\
0,05 \\
0,00 \\
0,39 \\
0,00\end{array}$ \\
\hline $\begin{array}{l}\text { Quartis } \\
\text { de renda }\end{array}$ & $\begin{array}{l}\text { q2 } \\
\text { q3 } \\
\text { q4 }\end{array}$ & $\begin{array}{l}(0,17) \\
(0,17) \\
(0,33)\end{array}$ & $\begin{array}{l}0,06 \\
0,06 \\
0,08\end{array}$ & $\begin{array}{l}(2,97) \\
(2,78) \\
(4,27)\end{array}$ & $\begin{array}{l}0,00 \\
0,01 \\
0,00\end{array}$ \\
\hline Regiões & $\begin{array}{l}\text { NO } \\
\text { NE } \\
\text { SUL } \\
\text { CO } \\
\text { Marido pensionista ou aposentado } \\
\text { cons }\end{array}$ & $\begin{array}{r}0,14 \\
0,10 \\
0,11 \\
0,03 \\
0,76 \\
(2,15)\end{array}$ & $\begin{array}{l}0,06 \\
0,05 \\
0,05 \\
0,06 \\
0,09 \\
0,12\end{array}$ & $\begin{array}{r}2,28 \\
1,94 \\
2,03 \\
0,44 \\
8,85 \\
(17,28)\end{array}$ & $\begin{array}{l}0,02 \\
0,05 \\
0,04 \\
0,66 \\
0,00 \\
0,00\end{array}$ \\
\hline
\end{tabular}

Fonte: IBGE. Pesquisa Nacional por Amostra de Domicílios - PNAD 2004.

(1) Corresponde somente à área urbana.

cipal provedora financeira, comparativamente àquelas em que as esposas possuíam de 0 a 3 anos de estudo (categoria de referência). ${ }^{11}$

Em termos regionais, as esposas de famílias situadas nas Regiões Norte, Nordeste e Sul do país possuíam maior chance de serem as provedoras, comparativamente àquelas localizadas no Sudeste, região que concentra o maior dinamismo econômico do país.

Com relação às ocupações dos cônjuges, as famílias em que os maridos eram trabalhadores agrícolas, os pior remunerados entre todos os grupos ocupacionais, apresentavam maior probabilidade de

\footnotetext{
${ }^{11}$ As variáveis dos grupos de escolaridade de 12 a 14 anos e 15 e mais anos de estudo foram significativas a $10 \%$ e $5 \%$ de significância, respectivamente. As demais variáveis dummy para grupos de escolaridade não foram estatisticamente significativas.
} 
possuírem esposa provedora, em relação aos trabalhadores dos serviços (categoria de referência). As famílias em que os maridos encontravam-se nas demais ocupações registraram menor probabilidade de terem as mulheres como principais provedoras. Com relação às mulheres, a lógica é inversa em relação às ocupações das esposas. As integrantes das Forças Armadas, dirigentes, professoras e técnicas aumentaram, em maior escala, a probabilidade de serem as provedoras quando comparadas àquelas ocupadas nos serviços. As trabalhadoras agrícolas, pior remuneradas entre todas as ocupações considerando esposas e maridos, diminuíram, em muito maior escala, a probabilidade de se tornarem provedoras quando relacionadas àquelas inseridas nos serviços.

Quanto à renda per capita familiar, as famílias que se situavam no primeiro quartil de renda possuíam maior probabilidade de terem as esposas como provedoras principais de renda, controlando-se pelas demais variáveis do modelo.

Por fim, entre os casais em que pelo menos um dos cônjuges se declarou não branco, a probabilidade de a esposa ser a principal provedora era maior do que para aqueles em que os dois se consideraram brancos. Possuir o marido como pensionista ou aposentado também aumentou a probabilidade de a esposa ser a provedora, depois de se controlar pelas demais variáveis do modelo.

\section{A análise dos rendimentos}

A análise descritiva dos rendimentos médios para esposas e maridos em famílias com duplo rendimento do casal, demonstrados na Tabela 3, indica que a renda

TABELA 3

Rendimentos médios, horas trabalhadas e rendimento/hora de esposas e maridos, por sexo do provedor principal do casal

Brasil (1) -2004

\begin{tabular}{|c|c|c|c|c|c|c|}
\hline $\begin{array}{l}\text { Rendimentos e } \\
\text { horas trabalhadas }\end{array}$ & $\begin{array}{c}\text { Casais } \\
\text { com esposas } \\
\text { provedoreas (a) }\end{array}$ & $\begin{array}{c}(E / M)-1 * 100 \\
(2)(a)\end{array}$ & $\begin{array}{c}\text { Casais com } \\
\text { maridos } \\
\text { provedores (b) }\end{array}$ & $\begin{array}{l}(E / M)-1 * 100 \\
(2)(b)(\%)\end{array}$ & $\begin{array}{l}\text { Total dos } \\
\text { casais (c) }\end{array}$ & $\begin{array}{l}(\mathrm{E} / \mathrm{M})-1 * 100 \\
(2)(\mathrm{c})(\%)\end{array}$ \\
\hline \multicolumn{7}{|c|}{$\begin{array}{l}\text { Rendimento mensal } \\
\text { de todos os trabalhos } \\
\text { (em } \mathrm{R} \$ \text { ) }\end{array}$} \\
\hline Esposa & $1.071,7$ & 72,0 & 461,0 & $-63,0$ & 662,6 & $-41,0$ \\
\hline Marido & 623,3 & & $1.249,7$ & & $1.125,7$ & \\
\hline \multicolumn{7}{|c|}{$\begin{array}{l}\text { Rendimento mensal do } \\
\text { trabalho principal } \\
\text { (em R\$) }\end{array}$} \\
\hline Esposa & 985,2 & 62,0 & 446,8 & $-62,0$ & 634,2 & $-41,0$ \\
\hline Marido & 607,8 & & $1.174,3$ & & $1.067,0$ & \\
\hline \multicolumn{7}{|c|}{ Horas trabalhadas (3) } \\
\hline Esposa & 39,8 & $-6,0$ & 34,9 & $-25,0$ & 37,2 & $-18,0$ \\
\hline Marido & 42,2 & & 46,4 & & 45,5 & \\
\hline \multicolumn{7}{|c|}{ Rendimento/hora (4) } \\
\hline Esposa & 6,8 & 62,0 & 3,6 & $-50,0$ & 4,8 & $-28,0$ \\
\hline Marido & 4,2 & & 7,2 & & 6,6 & \\
\hline \multicolumn{7}{|l|}{$\begin{array}{l}\text { Rendimento mensal } \\
\text { total (em R\$) }\end{array}$} \\
\hline Esposa & $1.121,9$ & 56,0 & 463,7 & $-65,0$ & 697,7 & $-41,0$ \\
\hline Marido & 718,2 & & $1.311,8$ & & $1.192,6$ & \\
\hline
\end{tabular}

Fonte: IBGE. Pesquisa Nacional por Amostra de Domicílios - PNAD 2004.

(1) Corresponde somente à área urbana.

(2) $E / M=$ Relação esposa/marido, em porcentagem.

(3) Número de horas trabalhadas no trabalho principal na semana de referência.

(4) [Rendimento mensal do trabalho principal/(horas semanais*4)]. 
mensal do trabalho principal da esposa provedora era $62 \%$ maior do que a de seu marido, ao passo que a da esposa coprovedora era $62 \%$ inferior à de seu marido. O rendimento do marido provedor era ainda $19 \%$ superior ao da esposa provedora.

Como o número médio de horas trabaIhadas da esposa provedora (40 horas) é menor do que o do seu marido (42 horas) e o do marido provedor (46 horas), analisaram-se também os rendimentos por hora trabalhada. Observa-se que o salário-hora da esposa provedora continua $62 \%$ maior do que o de seu marido e que a esposa coprovedora possui um salário-hora $50 \%$ inferior ao de seu marido (a esposa co-provedora possuía salário-hora ainda menor do que o do marido co-provedor). O saláriohora do marido provedor era aproximadamente $6 \%$ superior ao da esposa provedora.

\section{Esposas e maridos provedores: a decomposição da diferença dos rendimentos}

O modelo de regressão de Mínimos Quadrados Ordinários para equações salariais foi utilizado na decomposição dos diferenciais de rendimentos de maridos e esposas provedores, efetuada pelo método de Oaxaca, largamente utilizado nos estudos que procuram medir a discriminação no mercado de trabalho (LEME; WAJNMAN, 2001). Esta metodologia permite verificar quanto da diferença salarial se explica pelas diferenças observáveis entre dois grupos de indivíduos, e as diferenças não observáveis, ou não explicáveis, comumente atribuídas à discriminação.

O componente explicado da decomposição salarial é definido pelas diferenças médias nas características pessoais dos indivíduos, definidas pelas variáveis de controle determinadas para uma dada equação salarial. O componente não explicado, por sua vez, é definido pelas dife- renças nos coeficientes estimados, mesmo após controlar pelas características observáveis dos indivíduos, indicando a parcela do diferencial resultante da discriminação sofrida no mercado de trabalho. Alguns autores, entretanto, chamam a atenção para o fato de que qualquer variável de controle importante, não incluída no modelo, também afetará os coeficientes da equação salarial e, conseqüentemente, o componente não explicado da decomposição efetuada. $\mathrm{Da}$ mesma forma, a discriminação sofrida pelas pessoas pode definir as características observáveis dos indivíduos, como, por exemplo, a ocupação de postos no mercado de trabalho menos qualificados, não sendo, assim, captada pelo componente não explicado da decomposição (ALTONJI; BLANK, 1999). ${ }^{12}$

A diferença salarial, neste trabalho, foi medida através do log do rendimento médio mensal do trabalho principal de maridos e esposas provedores. $O$ conceito de provedor, então, passa a ser o do cônjuge que possui a maior renda do trabalho principal. As variáveis explicativas incluíram o número de horas semanais trabalhadas no trabalho principal, a idade do provedor, a idade ao quadrado, ${ }^{13}$ variável dummy para cor/raça (categoria de referência: branco), nove dummies para grupos ocupacionais (categoria de referência: trabalhadores dos serviços), quatro dummies para a região do país em que se encontram (categoria de referência: Sudeste) e cinco dummies para grupos de anos de estudo (categoria de referência: 0 a 3 anos de estudo).

A Tabela 4 traz os principais resultados da decomposição. Verifica-se que, se dependesse das características observáveis entre homens e mulheres, especificadas pelas variáveis dependentes do modelo da equação salarial, o log dos salários dos maridos provedores seriam inferiores aos das esposas provedoras em aproximadamente $17 \%$, devido, principalmente, à maior escolaridade das mulheres,

\footnotetext{
${ }^{12}$ Para formalização da decomposição salarial pelo método utilizado, ver Altonji e Blank (1999).

${ }^{13}$ Os coeficientes dos termos idade e idade ao quadrado, positivo e negativo, respectivamente, indicam a concavidade da curva de rendimento observado. Ela mostra que os ganhos nos rendimentos tendem a ser decrescentes com a idade.
} 
TABELA 4

Principais resultados da decomposição da diferença no log do salário do trabalho principal de maridos e esposas provedores, em casais com duplo rendimento do trabalho Brasil (1) - 2004

\begin{tabular}{lccc}
\hline \multicolumn{1}{c}{ Diferença no log do salário } & & & $\mathbf{0 , 1 3}$ \\
\hline \multicolumn{1}{c}{ Contribuição para a diferença } & Parte não explicada & Parte explicada & Total \\
\hline Idade & 0,19 & 0,08 & 0,27 \\
Idade`2 & $-0,03$ & $-0,08$ & $-0,10$ \\
Cor & 0,01 & 0,00 & 0,01 \\
Grupos ocupacionais & 0,03 & $-0,05$ & $-0,02$ \\
Regiōes & 0,00 & 0,01 & 0,02 \\
Escolaridade & & & \\
$\quad 4$ a 7 anos de estudo & 0,02 & 0,02 & 0,04 \\
8 a 11 anos de estudo & $-0,01$ & 0,00 & 0,00 \\
12 a 14 anos de estudo & 0,01 & $-0,04$ & $-0,03$ \\
15 e mais anos de estudo & 0,01 & $-0,15$ & $-0,14$ \\
Horas trabalhadas & $-0,36$ & 0,04 & $-0,32$ \\
Constante (2) & 0,40 & & 0,40 \\
Total & 0,29 & $-0,15$ & 0,13 \\
$\quad \%$ & 117,0 & $-17,0$ & 1,00 \\
\hline
\end{tabular}

Fonte: IBGE. Pesquisa Nacional por Amostra de Domicílios - PNAD 2004.

(1) Corresponde somente à área urbana.

(2) Termo constante obtido nas regressões, relacionado com a parte não explicada da decomposição.

notadamente do grupo de 15 e mais anos de estudo. No entanto, características não observáveis, entre as quais a existência de discriminação do mercado de trabalho em favor dos homens, mais do que compensam a diferença em favor das mulheres, reduzindo em $13 \%$ os rendimentos destas relativamente aos dos homens. ${ }^{14} \mathrm{Em}$ contraste com o total de esposas e maridos (e não apenas os provedores), a decomposição revela que a parte explicada é favorável aos homens, sobretudo pelo maior número de horas trabalhadas (bem maior do que entre esposas e maridos provedores). A escolaridade ainda prioriza as mulheres, mas perde relevância diante da diferença no número de horas trabalhadas.

\section{Considerações finais e agenda de estudos subseqüentes}

Com base nos dados da PNAD de 2004, verificou-se que, entre as famílias com casais com duplo rendimento do trabalho, aquelas nas quais as esposas eram as provedoras principais perfaziam 17\% (contra uma média de $20 \%$ a $25 \%$, indicada pela literatura internacional, em países desenvolvidos) (CROMPTON; GERAN, 1995; US BUREAU OF STATISCTICS, 2005; WINKLER et.al., 2005). Os rendimentos das esposas provedoras, quando analisados através dos rendimentos totais, do trabalho ou salário-hora dos cônjuges, eram menores do que os dos maridos provedores. Estas mulheres não só possuíam rendimentos superiores à média das outras esposas (as co-provedoras), como seus maridos também tinham rendimentos muito inferiores aos dos demais maridos (os provedores). Em relação aos maridos provedores, a decomposição da diferença salarial mostrou que ainda existe uma grande parte desta diferença não explicada pelas características observáveis, como idade, escolaridade, grupo ocupacional, região do país e

\footnotetext{
${ }^{14}$ Os rendimentos médios das esposas e maridos provedores são $\mathrm{R} \$ 1.024,00$ e $\mathrm{R} \$ 1.155,00$, respectivamente, e diferem daqueles descritos anteriormente, devido ao novo critério de provedor aqui assumido.
} 
número de horas trabalhadas, e que provavelmente está relacionada com a discriminação ainda presente no mercado de trabalho.

O fenômeno dos sobre-rendimentos das esposas, apesar de se concentrar na cauda inferior da distribuição de renda, não se restringia a ela. Estas informações são corroboradas pela regressão logística que mostrou que ser mais escolarizada, mais velha, estar em ocupações de melhor qualidade aumentavam a probabilidade de a esposa ser a provedora financeira do casal, ao mesmo tempo em que famílias situadas no quartil mais baixo da distribuição de renda também tinham maior probabilidade de terem a esposa como principal provedora.

Soma-se a isto o fato de que a mulher, por ser provedora, não se qualificava para ser dispensada de parte significativa dos afazeres domésticos. O tempo despendido pelo marido nestes trabalhos praticamente não mudou com relação à sua maior ou menor participação no orçamento familiar e correspondia, aproximadamente, à metade do tempo gasto pelas esposas.

Esta análise permitiu fazer algumas inferências sobre quem são as mulheres provedoras e o que as colocava nesta situação. Foi possível constatar, também, que estas mulheres acabam sendo duplamente penalizadas, porque, do ponto de vista doméstico, apesar de serem as provedoras financeiras, isto não as libera das tarefas familiares tradicionalmente femininas. Do ponto de vista do mercado

\section{Referências bibliográficas}

ATKINSON, M. P.; BOLES, J. WASP. Wives as senior partners. Journal of Marriage and the Family, n. 46, p. 861-870, 1984.

BARROS, R. P.; CORSEUIL, C. H.; SANTOS, D. D.; FIRPO, S. Diferenças por sexo e conseqüências sobre o bem-estar. Rio de Janeiro: Ipea, 2001 (Texto para discussão, 796). de trabalho, por outro lado, estas mulheres são discriminadas salarialmente, além de estarem sobre-representadas nos quartis mais pobres de renda, o que deprime o bemestar destas famílias comparativamente às tradicionais.

No entanto, tomando como referência a literatura internacional sobre o tema, ainda há muito a ser pesquisado. Em primeiro lugar, se carece de uma perspectiva intertemporal que indique como se comporta a proporção de casais com esposas provedoras através do tempo no Brasil. Estimativas preliminares confirmam que, como se espera, esta é uma tendência crescente. ${ }^{15}$

Contudo, também seria importante verificar se a condição de provedora das esposas na vida dos casais é transitória ou permanente $^{16}$ e quão vulneráveis estariam estas famílias com relação à perda de bemestar e suscetíveis ao empobrecimento, por não terem o homem como seu principal provedor. Vendo por um outro ângulo, também seria interessante verificar o impacto do rendimento das esposas no bem-estar das famílias e na distribuição de renda intra e entre as famílias.

Do ponto de vista qualitativo, é necessário entender melhor o efeito desta inversão dos papéis tradicionais na vida dos casais. Os estudos nessa linha na literatura internacional tendem a evidenciar o claro desconforto sentido por ambos os cônjuges nesta situação. Pouco se sabe sobre a forma como os casais brasileiros lidam com essa circunstância, mas é difícil supor que as coisas sejam mais fáceis por aqui.

BIANCHI, S. M.; ROBINSON P. J.; SAYER L.C. Family interaction, social capital, and trends in time use study. Universty of Mariland, Survey Research Center, College Park, 2001.

BITTMAN, M.; ENGLAND, P.; SAYER, L.; FOLBRE, N.; MATHESON, G. When does gender trump money? Bargaining and time

\footnotetext{
${ }^{15}$ Dados da PNAD indicam que havia, aproximadamente, 455 mil famílias cujas esposas eram as principais provedoras do casal em 1981, em contraste com 2.189 mil famílias, em 2004.

${ }^{16}$ Ver estudo de Winkler, McBride e Andrews (2005).
} 
in household work The American Journal of Sociology, 109, n. 1, July 2003.

BLUMBERG, R. L.; COLEMAN, M. T. A theoretical look at the gender balance of power in the American couple. Journal of Family Issues, n. 10, p. 225-250, 1989.

CROMPTON, S.; GERAN, L. Women as main wage-earners. Perspectives, Statistics Canadá - Catalogue 75-001E, 1995.

DEUTSCH, F. M.; ROKSA, J.; MEESKE, C. How gender counts when couples count their money. Sex Roles: a Journal of Research, April 2003.

GUIMARÃES, N.; BIDERMAN, C. Na antesala da discriminação: o preço dos atributos de sexo e cor no Brasil (1989 a 1999). Estudos Feministas, Florianópolis, 12(2): 264, maio-agosto, p. 177-200, 2004.

IZRAELI, D. N. Money matters: spousal incomes and family/work relations among physician couples in Israel. The Sociological Quarterly, n. 35, p. 69-84, 1994.

JOHN, D.; SHELTON, B. A. The production of gender among black and white women and men: The case of household labor. Sex Roles, n. 36, p. 171-193, 1997.

KAMO, Y. Determinants of household division of labor: resources, power, and ideology. Journal of Family Issues, n. 9, p. 177-200, 1988.

LAVINAS, L. Emprego feminino: o que há de novo e o que se repete. Dados. [online], v. $40,1997$.

LEME, M. C.; WAJNMAN, S. Diferenciais de rendimentos por gênero. In: LISBOA, M. B.; MENEZES FILHO, N. A. (Orgs.). Microeconomia e sociedade no Brasil. Rio de Janeiro: Contra Capa: FGV/EPGE, 2001, p.79-114.
LEME, M. C.; WAJNMAN, S. Tendências de coorte nos diferenciais de rendimentos por sexo. In: HENRIQUES, R. (Org.). Desigualdade e pobreza no Brasil. Rio de Janeiro: Ipea, dezembro 2000, p.251-270.

MOORE, M. Wives as primary breadwinners Perspectives on Labour and Income, v. 2, n.1, Article n.6, 1990.

OLIVEIRA, A.M.H.C. A segregação ocupacional por gênero e seus efeitos sobre os salários no Brasil. In: WAJNMAN, S.; MACHADO, A. F. (Orgs.). Mercado de trabalho: uma análise a partir das pesquisas domiciliares no Brasil. Belo Horizonte: Editora UFMG, 2003, p.121-150.

STEIL, J. Marital equality: its relationship to the well-being of husbands and wives. Thousand Oaks, CA: Sage, 1997.

US BUREAU OF STATISCTICS. Women in Labor Force: a databook 2005. Report 985, 2005.

WAJNMAN, S. Mulheres na sociedade e no mercado de trabalho brasileiro: avanços e entraves. Olhares femininos, mulheres brasileiras. Rio de Janeiro: X-Brasil, 2006 (Coleção Valores e Atitudes), no prelo.

WINKLER A. E.; MCBRIDE T. D.; ANDREWS C. Wives who outearn their husbands: a transitory or persistent phenomenon for couples? Demography, v. 42, n. 3, p. 523535, August 2005.

WINKLER, A. E. Earnigs of husbands and wives in dual-earner families. Monthly Labor Review, 1998.

ZUO, J. The effect of men's breadwinner status on their changing gender beliefs. Sex Roles, n. 37, p. 799-816, 1997.

\section{Resumen}

Esposas como principales proveedoras de la renta familiar

Este trabajo procura discutir un aspecto aún poco explorado del papel de la mujer en la formación de los rendimientos familiares, que es la situación en la cual las esposas obtienen, 
en el mercado de trabajo, rendimientos superiores a los de sus cónyuges. Además de la descripción de características demográficas y socio-ocupacionales de estas mujeres y de sus cónyuges, se busca discutir los siguientes aspectos: como algunas de las características observadas están correlacionadas con la probabilidad de que las familias tengan a las esposas como principales proveedoras; la no reversión de los estándares tradicionales de división del trabajo, ya que la mujer dedica un número de horas mucho mayor que sus cónyuges a las tareas domésticas, aún cuando es la principal proveedora financiera de la pareja; los diferenciales en el rendimiento promedio de maridos y esposas proveedores y la descomposición de este diferencial entre lo que puede ser atribuido a las características productivas de ambos grupos y lo que es generalmente llamado discriminación.

Palabras-clave: Esposas proveedoras. Rendimiento familiar. Desigualdad de rendimientos.

\begin{abstract}
Wives as the main household earners

In this article three questions related to wives who outearn their husbands in Brazil are examined. First we discuss the demographic and socio-economic characteristics associated with the probability that the wife will be the main earner. Second, the patterns of the division of labor among couples where the women are the primary earners are examined, especially as to whether the women spend more time on domestic work than their husbands. Third, we quantify differentials in income between wife and husband earners and examine how these differentials are explained by differences in (1) professional characteristics between men and women and (2) discrimination.
\end{abstract}

Key words: Wives as main earners. Family income. Income inequality.

Recebido para publicação em 22/02/2007.

Aceito para publicação em 31/05/2007. 
